\title{
Preoperative information for ICU patients to reduce anxiety during and after the ICU-stay: protocol of a randomized controlled trial [NCTO0I5I554]
}

\author{
Almuth Berg' ${ }^{1}$, Steffen Fleischer ${ }^{1}$, Michael Koller ${ }^{2}$ and Thomas R Neubert*1
}

Address: ${ }^{1}$ University Hospital Gießen and Marburg, Location Marburg, Germany and ${ }^{2}$ University Hospital Regensburg, Germany

Email: Almuth Berg - almuth.berg@staff.uni-marburg.de; Steffen Fleischer - steffen.fleischer@staff.uni-marburg.de; Michael Koller - koller@med.uni-marburg.de; Thomas R Neubert* - neubertt@med.uni-marburg.de

* Corresponding author

Published: 08 March 2006

BMC Nursing2006, 5:4 doi:10.1186/1472-6955-5-4
Received: 23 December 2005

Accepted: 08 March 2006

This article is available from: http://www.biomedcentral.com/l472-6955/5/4

(c) 2006Berg et al; licensee BioMed Central Ltd.

This is an Open Access article distributed under the terms of the Creative Commons Attribution License (http://creativecommons.org/licenses/by/2.0), which permits unrestricted use, distribution, and reproduction in any medium, provided the original work is properly cited.

\begin{abstract}
Background: According to current evidence and psychological theorizing proper information giving seems to be a promising way to reduce patient anxiety. In the case of surgical patients, admission to the intensive care unit (ICU) is strongly associated with uncertainty, unpredictability and anxiety for the patient. Thus, ICU specific information could have a high clinical impact. This study investigates the potential benefits of a specifically designed ICU-related information program for patients who undergo elective cardiac, abdominal or thoracic surgery and are scheduled for ICU stay.
\end{abstract}

Methods/Design: The trial is designed as a prospective randomized controlled trial including an intervention and a control group. The control group receives the standard preparation currently conducted by surgeons and anesthetists. The intervention group additionally receives a standardized information program with specific procedural, sensory and coping information about the ICU.

A measurable clinical relevant difference regarding anxiety will be expected after discharge from ICU. Power calculation ( $\alpha=0.05 ; \beta=0.20 ; \Delta=8.50$ score points) resulted in a required sample size of $N=120$ cardiac surgical patients $(n=60$ vs. $n=60$ ). Furthermore, $N=20$ abdominal or thoracic surgical patients will be recruited $(n=10$ vs. $n=10)$ to gain insight to a possible generalization to other patient groups.

Additionally the moderating effect of specific patient attributes (need for cognition, high trait anxiety) will be investigated to identify certain patient groups which benefit most.

Discussion: The proposed study promises to strengthen evidence on effects of a specific, concise information program that addresses the information needs of patients scheduled for ICU stay.

\section{Background}

Technological advances during the last decades in intensive care medicine made it possible to treat an increasing number of high risk surgical patients. Nevertheless, many patients awaiting elective surgery experience diffuse anxiety and a lack of subjective predictability regarding their 
stay on the intensive care unit. The psychological elements that become salient in the perioperative situation can be characterized as loss of control, irritation and uncertainty. These psychological elements are also known for contributing to postoperative complications such as delayed wound healing and an increased intake of sedatives and analgesics [1]. In addition, the strange and unfamiliar situation on the ICU in combination with sleep deprivation and ICU-noises is closely related with the incidence of a postoperative delirium also called ICU-Syndrome $[2,3]$. In a preliminary study it was shown that only $16 \%$ of the asked patients felt sufficiently informed and prepared for their ICU-stay [4].

According to the psychological theory of control proper preoperative information giving seems a promising way to reduce ICU-related anxiety [5-7].

A proper information program would inform the patient about the aims, prospects and the specific elements of the scheduled ICU stay. Thus, the patient learns that he/she is about to undergo a time-limited episode and that all is done in the best of his/her interest. This information together with learning about ways how to communicate in the case of specific needs gives the patient back a sense of control in this communicative difficult situation on the ICU.

A number of studies indicate that surgical patients profit from preoperative information with regard to various outcomes such as anxiety, pain and length of stay [8-17]. Nevertheless, the evidence that information regarding ICU-specific issues is beneficial is scarce [18-20] and a recent review concludes that randomised studies in this area are called for [18].

Therefore the aim of our study is to investigate the benefits of a standardized information program that prepared the patient for a scheduled ICU stay following an operation. This information program is tested in a randomized controlled trial, in which the control group receives the standard preoperative information and the intervention group the standard preoperative information plus the ICU-specific information.

The hypothesis of our study is straightforward: The information program reduces the experience of anxiety and other unpleasant emotions and cognitions that are related to the ICU stay. Furthermore we expect that the information program has a positive influence on quality of life and satisfaction with the hospital 3 months postoperatively.

\section{Methods/Design}

This trial is based on a non-blinded, randomized controlled study design. The control group receives the routine treatment and information by the surgeon and the anesthetist, the experimental group additionally receives an ICU-specific information program on the day before surgery.

\section{Inclusion and exclusion criteria}

The study is conducted in cooperation with the Department of Heart Surgery and the Department of Visceral, Thoracic and Vascular Surgery at the University Hospital Gießen and Marburg, Location Marburg, Germany. In principle, all patients of these surgical departments that await elective surgery with a planned subsequent admission to the intensive care unit are eligible for this study. Mainly patients that undergo coronary artery bypass surgery and valve replacement or high risk patients undergoing thoracotomy, gastrectomy, pancreatic surgery, laparatomy, and rectal extirpation fulfil these criteria. In addition, all patients must be over 18 years of age, fluent German speakers and capable of filling out questionnaires. Further exclusion criteria are: pregnancy, not able to complete a questionnaire, the inclusion in another ongoing clinical trial or submission to a surgical ICU within the last year (this latter criteria renders the impact of an information program less likely).

\section{Randomization}

A block-wise balanced randomization procedure will be used. The allocation to either the intervention or the control group can be found on cards that are sealed into opaque and consecutively numbered envelopes. These envelopes will be opened after the patient has finished the baseline questionnaire. Type of surgical department (heart surgery or visceral, thoracic, vascular surgery) is the only stratification factor and separate piles of envelopes will be prepared for these two groups of patients.

\section{Blinding of participants}

Because of the obvious nature of the intervention patients and field researchers cannot be blinded. Data entry and analysis will be conducted by a neutral researcher who was not involved in data acquisition. Group allocation will be concealed to the analyst until the final analysis of the defined primary and secondary outcomes.

\section{Study procedure for the individual patient}

The study procedure is designed to be compatible with the highly standardized therapy regime of cardiac surgery patients. The single sequences of surgery schedule, surgery, admission on ICU, admission for standard care and discharge are executed due to hospital specific processes (Figure 1). Determination of points of measurement was done according to compiled data of cardiac surgery 


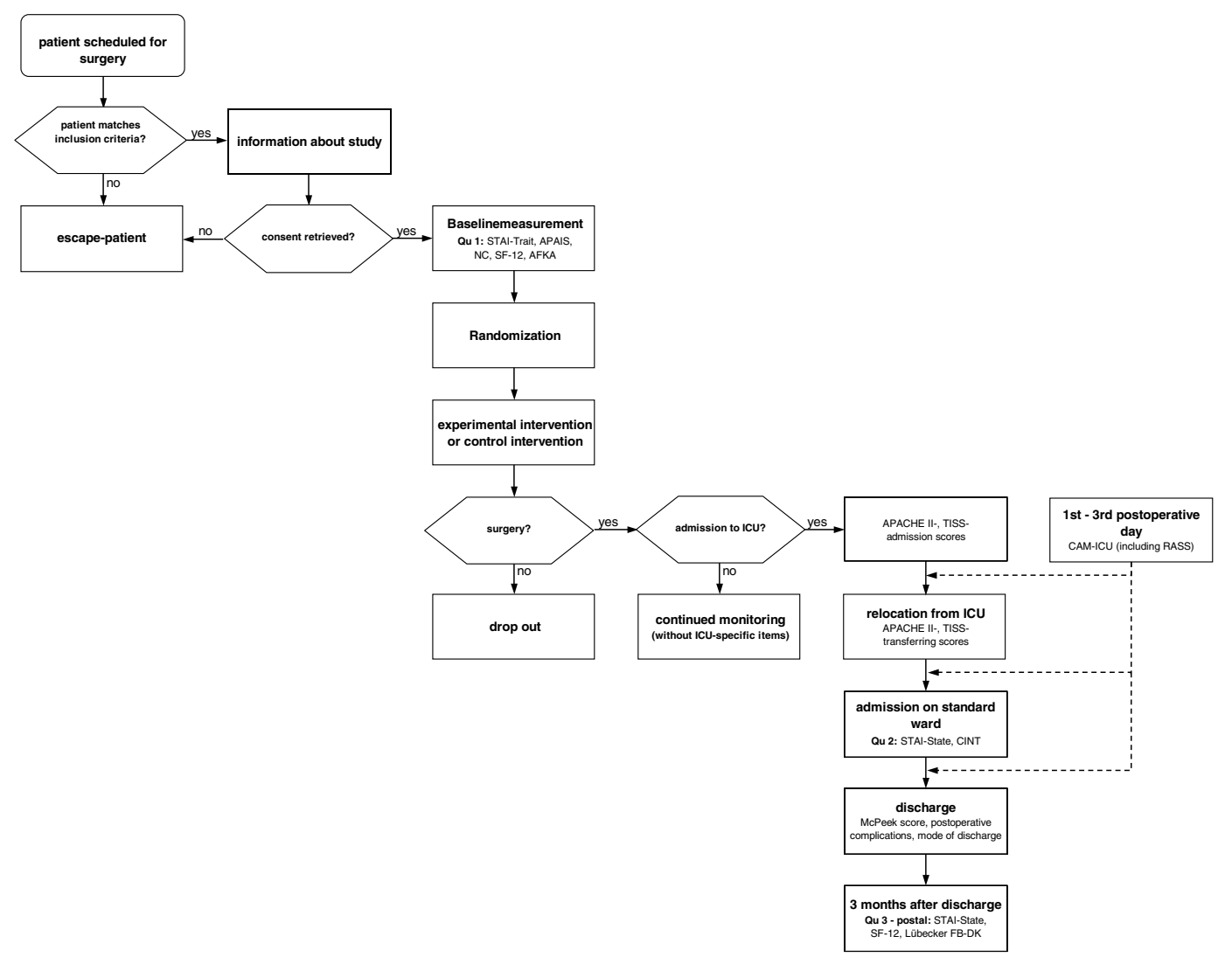

\section{Figure I}

Study procedures for the individual patient.

patients in the Marburg hospital. Patient recruitment is limited to 1 patient per day and department. By the use of a concealed randomized selection procedure with daily assigned random numbers a representative recruiting can be assured.

\section{Development of the information program}

In developing the ICU-specific information program, two main criteria were taken into account: comprehensibility and congruency to informational needs. In addition, empirical and theory based recommendations for patient information were considered [21]. Comprehensibility and congruency were accomplished by using the results of the preliminary studies, additional field observations and informal interviews on the involved wards and finally research literature on the experience of ICU-patients [3,22-32].
A pretest of the program then was carried out to further adapt and fine-tune it. This was done on $\mathrm{N}=22$ patients with elective ICU-stay [33].

The final program consists of two parts with procedural, sensorial and coping information specifically referring to the ICU-stay (Table 2). The first part is laid down as a standardized text; the verbal information is supplemented by two pictures showing relevant elements of the correspondent ICU. The second part of the program consists of seven cards that show the seven top rated fears associated with ICU-stay as they were named in the pretest. On the backside of the cards are short descriptions of what is done on ICU to counter the feared dangers.

Patients may choose cards that represent their fears and are then presented the fear-rebutting information on the 
back of the respective card. Furthermore, patients have the opportunity to ask additional open questions. The information program will take about 15 minutes and is given on the day before the scheduled surgery. The intervention is performed by one of the 2 researchers (each with diploma of Nursing and Health science and a registered nurse), who are not involved in the process of daily patient care.

\section{Measures}

\section{Self-rated measures}

The current emotional patient state is measured with the state-part of the German version of the State-Trait-Anxiety-Inventory (STAI) [34] after readmission to standard care (post-ICU) and 3 months after discharge. At the point of readmission to standard care unit, ICU-related experiences are assessed using the CINT, a scale specifically developed for these purposes and used in preliminary studies of our working group $[4,35,36]$.

Furthermore, health-related quality of life is measured using SF-12 [37] at baseline and 3 months after discharge. Also 3 months post-discharge patient satisfaction is measured using selected items from the Lübecker-FragebogenDoppelkarte [38]. Further baseline characteristics that are relevant to our research questions and distinguish between different types of patients are: Trait-Anxiety-Scale [34], preoperative need for information with the Amsterdam Preoperative Anxiety and Information Scale (APAIS) [39], a modified version of the Need-for-Cognition-Scale (NC) [40-43] to measure individual differences in cognitive preoccupation, and finally subjective illness conceptions using assorted items of the Aachener Fragebogen zur Krankheitsattribution (AFKA_I) [44].

\section{Observer-rated measures}

Postoperative confusion will be monitored on $1^{\text {st }}$ to $3^{\text {rd }}$ postoperative day using the Confusion Assessment Method for the ICU (CAM-ICU) $[45,46]$. This period was chosen as study results indicate the highest prevalence of postoperative confusion for cardiac surgery patients at these days $[47,48]$. This instrument is also applicable for mechanically ventilated patients and contains both cognitive and process-related elements. It covers the Richmond Agitation and Sedation Scale (RASS) [49] and 4 delirium characteristics: ,acute onset', ,inattention', ,disorganized thinking' und ,altered level of consciousness'.

As basic trial documentation pre- and post-surgical therapy data is recorded like length of stay, mode of discharge and complications. The Therapeutic Intervention Scoring System (TISS) [50] and the Acute Physiology and Chronic Health Evaluation II (APACHE II) [51] are documented at ICU admission and ICU discharge.
To quantify postoperative recovery the McPeek Recovery Score [52] will be calculated at the end of hospital stay.

Table 1 shows the timetable of the measures during the trial according to the case report form.

Self-rated measures were compiled according to the Total Design Method $[53,54]$ in order to achieve a high degree of study compliance. In addition, a cognitive pretest was executed $(\mathrm{N}=3)$ [55] to verify the properties of the questionnaires by oral interviews. Consequently, the study documentation and the questionnaires were adapted and in the pilot phase of the study a final standard-pretest $(\mathrm{N}$ $=5$ ) was done to test responsiveness and feasibility.

\section{Outcomes}

Primary outcome of our study is anxiety as measured by the anxiety-specific part of the CINT questionnaire. This scale relates to experienced anxiety on ICU and includes general anxiety, death related fear, fear of severe suffering, fear of a handicap, fear of the future, fear of uncertainty, panic, strain, depression, loneliness, lack of orientation, uncertainty and anger. All items are rated on a Likert-scale from 1 = never to 4 = always. This measure was specially developed for the reporting of ICU-related experiences and proved very useful in two previous studies $[4,35,36]$.

Secondary outcomes of the study are:

- incidence of postoperative confusion (ICU-CAM) within the first 3 postoperative days

- postoperative state anxiety (STAI) on standard care ward

- postoperative complications, length of stay and McPeek Recovery Score at discharge

- state anxiety (STAI) 3 months follow-up

- quality of life and self-reported health state (SF-12) 3 months follow-up

- patient satisfaction with care and hospital (items from the Lübecker-Fragebogen-Doppelkarte) 3 months followup.

\section{Sample size calculation}

Sample size calculation was performed with regard to the anxiety-specific part of the CINT questionnaire as the primary outcome. This score ranges between 0 and 100 with a standard deviation of SD $=17$ [36]. Setting alpha at 0.05 , beta at 0.20 and $\Delta=8.50$ (half a standard deviation as a clinically minimal relevant difference [56]) results in a required $N=100$ ( $n=50$ patients in each group) [57]. In order to compensate for possible drop-outs that definitive 
Table I: Points of measurement and clinical outcome measures according to case report form

\begin{tabular}{|c|c|}
\hline points of measurement & clinical outcome measures \\
\hline baseline (pre-intervention) & STAI-Trait', APAIS', SF-I2', NC-items' ${ }^{1}$, AFKA_I-items ${ }^{1}$, case report ${ }^{2}$ \\
\hline admission to ICU & TISS 2 , APACHE II2 (admission scores) \\
\hline Ist - 3rd postoperative day a. $\mathrm{m}$. & CAM-ICU (including RASS) ${ }^{2}$ \\
\hline relocation from ICU & TISS $^{2}$, APACHE $\|^{2}$ (transferring scores) \\
\hline admission on standard ward & STAI-State', CINT-items' \\
\hline discharge from hospital & McPeek recovery score ${ }^{2}$, postoperative complications ${ }^{2}$, length of stay ${ }^{2}$, mode of discharge ${ }^{2}$ \\
\hline 3 months after discharge (postal) & STAI-State', SF-I2', items from Lübecker FB-DK' \\
\hline
\end{tabular}

number of patients to be included into this trial will be set at $\mathrm{N}=120$. This number relates to patients of the Department of Heart Surgery, a relatively homogenous group of patients.

In order to generalize findings over a wider group of patients, an additional $\mathrm{N}=20$ from the Department of Visceral, Thoracic and Vascular Surgery will be recruited.

\section{Drop-outs}

Drop-outs will be documented thoroughly and included in data analysis to the point of drop-out. Sensitivity analysis will be undertaken assuming different models of outcome for the drop-outs.

\section{Data analysis}

First of all the whole trial data will be analyzed using descriptive methods: mean, median, standard deviation, frequencies including graphical presentation. Statistical testing will be focused on the cardiac surgery group $(\mathrm{n}=$ $120 ; 60$ vs. 60). The main hypothesis representing the primary outcome will be tested with a two-sided t-test for independent samples assuming; the level of statistical significance is set at alpha 0.05 (two-tailed). Secondary outcomes will be tested accordingly.

An important internal analysis will be the correlation of certain individual characteristics to measure which patients benefit more from the information program than others. Especially "need for cognition" and "APAIS" measured at baseline are expected to moderate the impact of the intervention program. This will be analyzed by comparing means of subgroups using the t-test and regression modeling. This is a new study question never investigated in research on preoperative information programs.

Statistical analyses will be performed on an intention to treat basis and will be supplemented using a per protocol approach. The smaller group of patients from the Department of Visceral, Thoracic and Vascular Surgery will be analyzed using descriptive statistics and the main purpose will be to see whether the distribution of crucial outcome parameters resembles the pattern of data found in the cardiac surgery patients.

All analyses will be performed using the SPSS for Windows software.

\section{Quality assessment}

The trial is part of the Nursing Research Network "MitteSüd". A report system is established within the network. Quarterly and annual quality reports have to be prepared. These reports undergo peer review and further funding is contingent on a positive review.

\section{Ethical considerations}

The study protocol has been submitted to and approved by the ethical committee of the University Hospital Marburg.

The study relates to a research question that is still unresolved in the literature (equipoise; i.e. it is uncertain

Table 2: Topics of the information program

\begin{tabular}{ll}
\hline I) standardized part with information to the following aspects: & 2) individualized part with detailed information to the specific fears: \\
\hline - How do you get to the operation theatre and the ICU? & - fear of complications \\
- Who is responsible for you on ICU? & - fear of feeling locked in \\
- What are the devices for? & - fear of being helpless and dependent on others \\
- How does it look like being patient on the ICU? & - fear of pain \\
- What is the probable schedule of the ICU-stay? & - fear of suffocation \\
- How can you call attention to your needs? & - fear of death or never waking up again \\
- What else is done for you? & - fear of being lonesome \\
- What can you do if you feel stressed? & \\
\hline
\end{tabular}


whether the intervention or the control group will benefit) and the most rigorous method to settle this issue is the randomized controlled clinical trial. According to the experience in previous trial, participating in a study like this is unlikely to be burdensome for patients $[18,4,35,36]$. Patients will be fully informed about the purpose of the trial and informed consent is required. All study data is kept locked and anonymous i.e. stored and evaluated using encrypted numbers. The allocation of the patients is documented in a separate reference list that is accessible only to the implementing study personnel.

\section{Discussion}

A measurable, clinically relevant difference in the reduction of anxiety through a preoperative ICU-related information program is expected. Beyond that, interindividual differences in emotional and cognitive preoccupation will be considered that might moderate the impact of information programs and will allow to select patients that may profit most.

\section{Competing interests}

The author(s) declare that they have no competing interests.

\section{Authors' contributions}

$\mathrm{AB}, \mathrm{SF}, \mathrm{MK}$ and TRN contributed to the development of the study protocol. All authors were responsible for the drafting of this paper and approved the final manuscript.

\section{Acknowledgements}

The trial is funded by the Federal Ministry of Education and Research (BMBF grant 0IGT0303) as project P6 of the German Nursing Research Network "Mitte-Süd".

The authors thanks the members of the study group: R. G. Moosdorf, M. Rothmund, I. Celik, I. Hassan, A. Zielke, U. Töllner-Bauer, E. Freyenhagen and the advisory board: H.-D. Basler, J. Rochon, M. Schäg, N. DonnerBanzhoff, J. Haerting, J. Behrens.

\section{References}

I. Cole-King A, Harding KG: Psychological factors and delayed healing in chronic wounds. Psychosom Med 2001, 63:216-220.

2. Ewers A, Osterbrink J: Akute postoperative Verwirrtheit: Ein bekanntes Phänomen mit großen Unbekannten. Pflege Z 2003, 56:349-352.

3. Liedtke A: Die blaue Mafia: Subjektives Erleben von Patienten bei Langzeitintensivtherapie. Intensiv- und Notfallbehandlung 2002, 27:77-83.

4. Neubert TR, Koller M, Bohrer T: Wie erleben Patienten den Aufenthalt auf einer chirurgischen Intensivstation? Eine prospektive Beobachtungsstudie aus Sicht der Pflege. Intensiv 2004, I 2: 1- I0.

5. Frey D, Jonas E: Die Theorie der kognizierten Kontrolle. In Theorien der Sozialpsychologie. Motivations-, Selbst- und Informationsverarbeitungstheorien Edited by: Frey D, Irle M. Bern, Huber; 2002:I3-50.

6. Teasdale K: Information and anxiety: a critical reappraisal. J Adv Nurs 1993, 18: I I25-1 I32

7. Shuldham C: A review of the impact of pre-operative education on recovery from surgery. Int J Nurs Stud 1999, 36: I71-177.

8. Anderson EA: Preoperative preparation for cardiac surgery facilitates recovery, reduces psychological distress, and reduces the incidence of acute postoperative hypertension. J Consult Clin Psychol 1987, 55:5I 3-520.

9. Arthur HM, Daniels C, McKelvie R, Hirsh J, Rush B: Effect of a preoperative intervention on preoperative and postoperative outcomes in low-risk patients awaiting elective coronary artery bypass graft surgery. A randomized, controlled trial. Ann Intern Med 2000, I33:253-262.

10. Shi SF, Munjas BA, Wan TT, Cowling WR, Grap MJ, Wang BB: The effects of preparatory sensory information on ICU patients. J Med Syst 2003, 27:191-204.

II. Shuldham CM, Fleming S, Goodman H: The impact of pre-operative education on recovery following coronary artery bypass surgery. Eur Heart J 2002, 23:666-674.

12. Devine EC: Effects of psychoeducational care for adult surgical patients: a meta-analysis of $19 \mathrm{I}$ studies. Patient Educ Couns 1992, 19:129-142.

13. Devine EC, Cook TD: A meta-analytic analysis of effects of psychoeducational interventions on length of postsurgical hospital stay. Nurs Res 1983, 32:267-274.

14. Hathaway D: Effect of pre-operative instruction on post-operative outcomes: a meta-analysis. Nurs Res 1986, 35:269-275.

15. McDonald S, Green SE, Hetrick S: Pre-operative education for hip or knee replacement (Review). The Cochrane Database of Systematic Reviews 2004.

16. Martin D: Pre-operative visits to reduce patient anxiety: a study. Nurs Stand 1996, 10:33-38.

17. Krohne HW, El-Giamal M, Volz C: Der Einfluss sozialer Unterstützung auf die prä- und postoperative Anpassung chirurgischer Patienten. Zeitschrift für Gesundheitspsychologie 2003, I I: I 32- I 42.

18. Scott A: Managing anxiety in ICU patients: the role of preoperative information provision. Nurs Crit Care 2004, 9:72-79.

19. Shuldham CM: Pre-operative education - a review of the research design. Int J Nurs Stud 1999, 36:179-187.

20. Shuldham CM: Pre-operative education for the patient having coronary artery bypass surgery. Patient Educ Couns 2001, 43:129-137.

21. Ley P: Giving information to patients. In Social psychology and behavioral science Edited by: Eiser JR. New York, John Wiley \& Sons, Ltd; 1982:339-373.

22. Granberg A, Bergbom Engberg I, Lundberg D: Patients' experience of being critically ill or severely injured and cared for in an intensive care unit in relation to the ICU syndrome. Part I. Intensive Crit Care Nurs 1998, I 4:294-307.

23. Granberg A, Bergbom Engberg I, Lundberg D: Acute confusion and unreal experiences in intensive care patients in relation to the ICU syndrome. Part II. Intensive Crit Care Nurs 1999, I 5:19-33.

24. Hunt JM: The cardiac surgical patient's expectations and experiences of nursing care in the intensive care unit. Aust Crit Care 1999, I 2:47-53.

25. Klein M, Kellner K: Interaktionen zwischen Intensivstationspatienten: Vergleich verschiedener Intensivstationen. Prakt Anaesth 1979, I4:406-4II.

26. Nydahl P: Wie erleben Patienten die Intensivstation? Eine pflegerische Studie. Intensiv 1996, 4:250-254.

27. Roth-Isigkeit A: Wie erleben postoperative, herzchirurgische Patienten die pflegerische Versorgung auf der Intensivstation? Intensiv 2001, 9:24-29.

28. Russell S: An exploratory study of patients' perceptions, memories and experiences of an intensive care unit. J Adv Nurs 1999, 29:783-791.

29. Schreiner M, Weiss G: Was Patienten in der Intensivstation wahrnehmen und erleben. Pflege Z 2004, 57:4-9.

30. Ullrich L: Die Erfahrungen einer Patientin auf der Intensivstation - ein Erlebnisbericht anhand eines geführten Interviews. Intensiv 1996, 4:21-23.

31. Watts S, Brooks A: Patients' perceptions of the pre-operative information they need about events they may experience in the intensive care unit. J Adv Nurs 1997, 26:85-92.

32. Wong FY, Arthur DG: Hong Kong patients' experiences of intensive care after surgery: nurses' and patients' views. Intensive Crit Care Nurs 2000, I 6:290-303.

33. Berg A, Fleischer S, Neubert T, Koller M: Entwicklung und Pretest eines Programms mit spezifischen Informationen zum 
Intensivstationsaufenthalt. Hallesche Beiträge zu den Gesundheitsund Pflegewissenschaften 2004, 3:18-20.

34. Laux L, Glanzmann P, Schaffner P, Spielberger CD: STAI - Das StateTrait-Angstinventar. Theoretische Grundlagen und Handanweisung Weinheim, Beltz Testgesellschaft; 198I.

35. Bohrer T, Koller M, Neubert T, Moldzio A, Beaujean O, Hellinger A, Lorenz W, Rothmund M: Wie erleben allgemeinchirurgische Patienten die Intensivstation? Ergebnisse einer prospektiven Beobachtungsstudie. Chirurg 2002, 73:443-450.

36. Neubert TR: Patients' emotional experiences of ICU. A randomised controlled trial. In Abstractbook. I2th Biennial Conference of the Workgroup of European Nurse Researchers Lisbon/Portugal. 05.10.-08.10.2004

37. Bullinger M, Kirchberger I: SF-36, Fragebogen zum Gesundheitszustand: Handanweisung Göttingen, Hogrefe; 1998

38. Klinger M, Bürk C, Dombert T, Viethen G: Erste Erfahrungen mit der Lübecker Fragebogen-Doppelkarte zur Messung von Patienten(un)zufriedenheit. Klinik \& Forschung 1996, 2:26S2-29S2

39. Moerman N, van Dam F, Muller MJ, Oosting H: The Amsterdam preoperative anxiety and information scale (APAIS). Anesth Analg 1996, 82:445-45I.

40. Cacioppo JT, Petty RE, Kao CF: The efficient assessment of need for cognition. J Pers Assess 1984, 48:306-307.

41. Bless H, Wänke M, Bohner G, Fellhauer RF, Schwarz N: Need for Cognition: Eine Skala zur Erfassung von Engagement und Freude bei Denkaufgaben. Zeitschrift für Sozialpsychologie 1994, 25:147-154.

42. Epstein S, Pacini R, Denes-Raj V, Heier H: Individual differences in intuitive-experiential and analytical-rational thinking styles. I Pers Soc Psychol 1996, 7 I:390-405.

43. Keller J, Bohner G, Erb HP: Intuitive und heuristische Urteilsbildung - verschiedene Prozesse? Präsentation einer deutschen Fassung des 'Rational-Experiential Inventory' sowie neuer Selbstberichtskalen zur Heuristiknutzung. Zeitschrift für Sozialpsychologie 2000, 3 1:87-101.

44. Wälte D, Kröger F: Aachener Fragebogen zur Krankheitsattribution (AFKA) Klinik für Psychosomatik und Psychotherapeutische Medizin, Universitätsklinikum der RWTH Aachen; 1995.

45. Ely EW, Margolin R, Francis J, May L, Truman B, Dittus R, Speroff T, Gautam S, Bernard GR, Inouye SK: Evaluation of delirium in critically ill patients: validation of the confusion assessment method for the intensive care unit (CAM-ICU). Crit Care Med 2001, 29:1370-1379.

46. Ely EW, Truman B: The confusion assessment method for the ICU (CAMICU): training manual Nashville, Vanderbilt University Medical Center; 2002.

47. Eriksson M, Samuelsson E, Gustafson Y, Aberg T, Engström KG Delirium after coronary bypass surgery evaluated by the organic brain syndrome protocol. Scand Cardiovasc J 2002, 36:250-255

48. Osterbrink J, Mayer H, Fiedler C, Ewers A, Haslbeck J, Wirth K, Wordel A, Hannich HJ, McDonough J, Krian A, Laczkovics A, Weyand M, Evers GC: Inzidenz und Prävalenz postoperativer akuter Verwirrtheit kardiochirurgischer Patienten nach Bypassoperationen sowie Herzklappenersatz. Pflege 2002, 15:178-I89.

49. Sessler CN, Gosnell M, Grap MJ, Brophy GT, O'Neal PV, Keane KA, Tesoro EP, Elswick RK: The richmond agitation-sedation scale: validity and reliability in adult intensive care patients. $\mathrm{Am} J$ Respir Crit Care Med 2002, 166:1338-1344.

50. Keene $A R$, Cullen $D J$ : Therapeutic intervention scoring system: update 1983. Crit Care Med 1983, I I: I-3.

51. Knaus W, Draper E, Wagner D, Zimmermann J: APACHE II: a severity of disease classification system. Crit Care Med 1985, 13:818-829.

52. McPeek B, Gasko M, Mosteller F: Measuring outcome from anesthesia and operation. Theor Surg 1986, I:2-9.

53. Dillman DA: Mail and telephone surveys: the total design method New York, Wiley; 1978.

54. Dillman DA: Mail and other self-administered questionnaires. In Handbook of survey research Edited by: Rossi PH, Wright JD, Anderson AB. Boston, Academic Press; 1983:359-378.

55. Prüfer $P$, Rexrodt M: Zwei-Phasen-Pretesting ZUMA-Arbeitsbericht 2000/08; 2000.
56. Norman GR, Sloan JA, Wyrwich KW: Interpretation of changes in health-related quality of life: the remarkable universality of half a standard deviation. Med Care 2003, 41:582-592.

57. Cohen J: Statistical power analysis for the behavioral sciences New York, Academic Press; 1977.

\section{Pre-publication history}

The pre-publication history for this paper can be accessed here:

http://www.biomedcentral.com/1472-6955/5/4/prepub
Publish with Biomed Central and every scientist can read your work free of charge

"BioMed Central will be the most significant development for disseminating the results of biomedical research in our lifetime. " Sir Paul Nurse, Cancer Research UK

Your research papers will be:

- available free of charge to the entire biomedical community

- peer reviewed and published immediately upon acceptance

- cited in PubMed and archived on PubMed Central

- yours - you keep the copyright

Submit your manuscript here:

http://www.biomedcentral.com/info/publishing_adv.asp
BioMedcentral 